\title{
Number of people with glaucoma worldwide
}

\author{
Harry A Quigley
}

\begin{abstract}
Aim-To estimate the prevalence of glaucoma among people worldwide. Methods-Available published data on glaucoma prevalence were reviewed to determine the relation of open angle and angle closure glaucoma with age in people of European, African, and Asian origin. A comparison was made with estimated world population data for the year 2000 . Results-The number of people with primary glaucoma in the world by the year 2000 is estimated at nearly $66 \cdot 8$ million, with 6.7 million suffering from bilateral blindness. In developed countries, fewer than $50 \%$ of those with glaucoma are aware of their disease. In the developing world, the rate of known disease is even lower.

Conclusions-Glaucoma is the second leading cause of vision loss in the world. Improved methods of screening and therapy for glaucoma are urgently needed. (Br f Ophthalmol 1996; 80: 389-393)
\end{abstract}

Glaucoma is a common visual disorder whose frequency among people of the world has not been analysed comprehensively. Open angle glaucoma (OAG) is a slowly progressive atrophy of the optic nerve, characterised by loss of peripheral visual function and an excavated appearance of the optic disc by ophthalmoscopy. ${ }^{1}$ The causes of OAG are not clear, though the intraocular pressure (IOP) is a risk factor. An abnormally high IOP level is not an effective diagnostic criterion for OAG, since some of those affected have IOP within the normal range. ${ }^{2}$ The high cost of present methods for glaucoma screening are a barrier to the identification of people at high risk for glaucoma blindness.

While an acute form of primary angle closure glaucoma (ACG) produces pain and decreased vision, ACG is often an asymptomatic disorder. ACG eyes are smaller than normal in length and anterior chamber depth, ${ }^{3}$ features that have been suggested for diagnostic screening.

This report examines all published reports of the prevalence of glaucoma in populations from many countries. Its specific aims are to estimate the prevalence of OAG and ACG among people of the major ethnic groups of the world and to account for its variation by age. These estimates are used to enumerate those expected to have glaucoma by the year 2000 .

\section{Methods}

In 111 published reports on the prevalence of glaucoma, ${ }^{4}$ I evaluated whether each study had the following desirable design features: random selection among the subject population, a high rate of examination of the sample, and a clear definition of glaucoma (including either optic disc examination or a visual field test). These three desirable features were required for a study to be included in this analysis. Studies were not included if elevated IOP or low visual acuity at screening were the sole criteria for definitive examination.

United States Census Bureau estimates for world population in the year 2000 were used, divided by 5 year age groups and by sex. The countries of the world were placed in regional groups that were expected to be similar in glaucoma prevalence. These were named: China (People's Republic of China, Taiwan, Hong Kong, Macau), India (India, Pakistan, Bangladesh, Afghanistan, Iran, Nepal), South Asia (Asian states not in China or India groups, Oceania), Near East (African states not in Africa group, Arab states), Africa (African states south of $20^{\circ} \mathrm{N}$ latitude, Caribbean nations with majority of African derivation, African Americans), Latin America (Mexico, Central and South American states, Caribbean states not in Africa group), and European derived (United States, Canada, Europe, former Soviet states, Australia, New Zealand).

In each region, data were evaluated from surveys that cited age specific OAG and ACG prevalences. For groups with insufficient population based prevalence data, estimates from hospital based data were used. The equation representing the best fit for existing estimates of glaucoma prevalence from individual surveys was used to generate a model of age specific and ethnic group specific prevalence estimates for the purposes of estimating global numbers of people with glaucoma.

\section{Results}

EUROPEAN DERIVED PEOPLE

In the detailed analysis of studies among European derived people, the best fit of OAG prevalence ${ }^{5-23}$ related to age is an exponential 


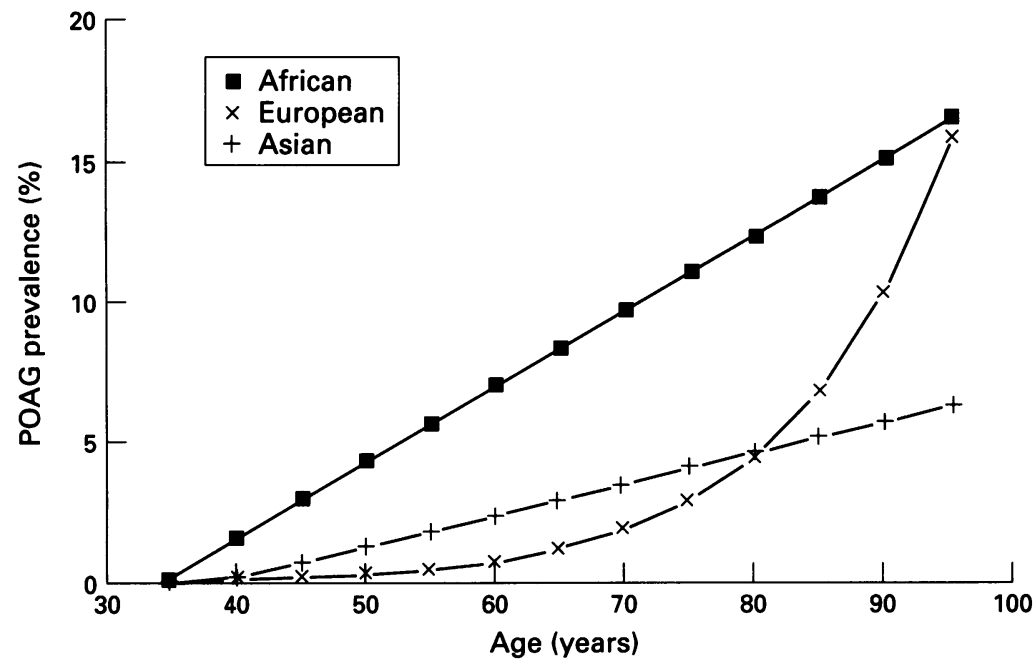

Figure 1 The prevalence of open angle glaucoma in European, African, and Asian people by age. a South African group with both Asian and African heritage. ${ }^{35}$ The age specific data suggest a linear relation of OAG to age in Asians: prevalence $=0.11$ (age) $-4.22\left(r^{2}=0.75\right)($ Fig 1$)$. This was applied to the China, India, and South Asia groups, though there are no available data on the latter two regions.

In available survey data, in blindness prevalence data, and in clinical reports from Asia, ${ }^{36-40}$ ACG appears more common among Chinese people than any other ethnic group. Their ratio of ACG to OAG approaches $3: 1 .^{33} 34$ The estimates assume the same slope of ACG with age as that for OAG, but with a rate three times higher among the China group. For India and South Asia groups, the slope and prevalence for ACG and OAG are assumed to be equal. Despite reports that ACG may be more common in women than in men, there are few survey data to support this conclusion; no sex difference is assumed. The practical consequence of this assumption is minimal, since in Asia, Latin America, and the Near East, the numbers of adult men and women are similar.

function: prevalence $(\%)=0.0059 \times \mathrm{e}^{0.08}$ (adjusted $r^{2}=0.70$ ) (Fig 1). In this modelling weights were assigned to data points to take account of the variance in prevalence, indicated by the number of cases and the total population. The mean age adjusted prevalence for adult European derived people (over age 40 ) was $2 \cdot 42 \%$ (SD $2 \cdot 10 \%$ ). In this estimate, the data from surveys of people of European derivation ${ }^{5-23}$ were applied to the population data of those defined here as European derived. OAG here includes those with normal and elevated levels of IOP. The diagnosis required evidence that either functional visual loss or structural damage to the optic disc was present. The ratio of males to females suggested no consistent sex difference (mean male/female ratio $=1 \cdot 1$ (SD 0.7 ) $(n=13) .6-81012$ 14-17 $1921-23$

The age adjusted prevalence for ACG in nine studiess-7 10-12 192123 averaged $0 \cdot 20 \%$ (SD $0.20 \%$ ) in those over 40 years. This is 11.4 times lower than the OAG prevalence in the same reports. Since the data were insufficient to estimate an age prevalence relation, it was assumed that ACG has the same exponential age relation as OAG, but 11.4 times lower. Males and females were presumed to be equally affected, as the stratification by sex produces groups too small for analysis.

AFRICAN DERIVED PEOPLE

The analysis of surveys ${ }^{21}$ 24-29 of OAG among African derived people was provided previously. ${ }^{4}$ The prevalence/age relation is linear: prevalence $=0.27$ (age) $-0.22 \quad\left(r^{2}=0.52\right)$ (Fig 1). ACG is rare in those of African descent, both in survey and clinic based data. ${ }^{30}$ The conclusion used here is that Africans have one half the European rate of ACG.

ASIAN PEOPLE

Population based studies of glaucoma prevalence in Asia include one report in 9000 Japanese people, ${ }^{31}$ a study in Beijing, China, ${ }^{32}$ a study of Chinese in Taiwan, ${ }^{33} 34$ and a study of

\section{LATIN AMERICA, NEAR EAST}

The estimation of glaucoma prevalence in Latin America and the Near East is conjectural, with no reason to assume that $O A G$ is more or less common than among Europeans. ${ }^{41-44}$ Therefore, the European rate is assigned. Among both groups, clinical reports and hospital based data suggest that ACG may be more common than among Europeans. For example, in Saudi Arabia, clinical records of consecutive glaucoma patients were categorised by subspecialty trained ophthalmologists. OAG was diagnosed in $60 \%(122 / 203)$ and ACG in $31 \%(63 / 203)$ (personal communication). For this analysis, the rate of ACG in these groups was estimated at five times the rate of ACG in the European derived group.

SECONDARY AND CHILDHOOD GLAUCOMA

Few studies describe secondary glaucoma as a separate entity and some investigators do not provide the criteria used in its definition. Those with pigmentary and exfoliation (or capsular) glaucoma are included here as primary OAG. The mean prevalence for secondary glaucoma in eight studies (including European, African, and Asian people) 71011192124272931 is $0.44 \%$ (SD $0.36 \%$ ), or $18 \%$ of the mean OAG prevalence in Europeans. The number of children with glaucoma is apparently quite small relative to that in adults, with little population based data to provide estimates. They are not included in this presentation, though it is recognised that the number of years during which blind children might live gives disproportionate importance to their visual disability.

DIAGNOSED VERSUS UNKNOWN GLAUCOMA The number of those with glaucoma who were previously diagnosed before each survey was compared with the number with newly 
Table 1 Estimate of number of people affected by glaucoma worldwide

\begin{tabular}{lrrr}
\hline Group & Open angle & Angle closure & Total population \\
\hline China & $\mathbf{7 4 4 4 6 6 3}$ & 22333990 & $\mathbf{1 2 8 8 7 0 4 3 1 4}$ \\
India & $\mathbf{5 5 9 1 0 4 2}$ & 5591042 & 1435699181 \\
South Asia & $\mathbf{4 2 2 4 8 1 9}$ & $\mathbf{4 2 2 4 8 1 9}$ & $\mathbf{7 6 9 9 7 9 5 7 0}$ \\
Europe & 6945870 & 609287 & 1116845880 \\
Africa & $\mathbf{7 0 2 6 0 8 1}$ & 46285 & $\mathbf{7 2 3 8 3 4 2 4 4}$ \\
Latin America & 1278751 & 560856 & 506533880 \\
Near East & 640040 & 280719 & 323624981 \\
$\begin{array}{l}\text { Total } \\
\text { Total primary } \\
\quad \text { glaucoma }\end{array}$ & 33151266 & 33646997 & 6165222154 \\
\hline
\end{tabular}

discovered disease. This varied from no known cases to $79 \%$ previously diagnosed, with a mean of $45 \%$ (SD $25 \%$ ) known cases $(n=14$ surveys $\left.^{6-14} 171921-23\right)$. Since most data were from studies in European derived people, it is likely that the number of known cases is fewer in developing countries.

\section{NUMBER OF PEOPLE WITH GLAUCOMA}

WORLDWIDE

The age data for seven world regions by 5 year group for the year 2000 were applied to the prevalence figures described above (Table 1). This suggests that 66.8 million people have OAG and ACG in nearly equal numbers. An additional 6.0 million people are estimated to have secondary glaucoma. The majority of ACG is in Asia, while OAG is more equally distributed.

It is important to estimate the number of those expected to be blind from glaucoma (disability/case ratio). In surveys from the European derived group, the rates of acuity of $20 / 200$ or worse in the better eye as a result of glaucoma were: $2.5 \%$ (Wisconsin, USA, B Klein, personal communication), $4 \cdot 4 \%$ (Baltimore, USA), ${ }^{21}$ and $6.2 \%$ (Roscommon, Ireland). ${ }^{7}$ Unfortunately, some studies provide only data with blindness indicated at the 20/200 level, rather than including the World Health Organisation standard of $<20 / 400$ (3/60). For African Americans, blindness occurred in $7 \cdot 9 \%(\leqslant 20 / 200(3 / 300)) .^{21}$ At a value of $10 \%$ blindness per case, 6.7 million people are estimated to be blind from glaucoma worldwide.

The comparison of glaucoma by age among regions reveals interesting differences. The total populations in the Africa and Europe groups are similar ( 723 million and $1 \cdot 1$ billion, respectively) and their OAG total numbers are similar ( 7 million and 6.9 million). However, owing to the earlier development of disease, the higher prevalence at younger ages, and differing demographic profiles, the distribution of disease by age is dramatically different in the two groups (Fig 2). The burden of disease is substantially higher among younger people in the Africa group.

\section{Discussion}

There are few earlier estimates of the number with glaucoma among the various ethnic groups in the world. ${ }^{45} 46$ Estimates of glaucoma prevalence that are based in part on blindness surveys ${ }^{46}$ might understate glaucoma prevalence, since both OAG and ACG affect visual acuity only at the last stage of their damage. Thylefors and Negrel $^{46}$ estimated a global glaucoma blindness figure of $5 \cdot 2$ million people. Their estimate of the number affected by glaucoma (about 20 million) was substantially lower than the estimate in this report. It is not possible to determine the differences between the models in the two reports, as the detailed values for prevalence by ethnic group and region are not given in their brief report. They assumed a bilateral blindness/case proportion of $23 \%$. However, among disease prevalence studies in European derived people, bilateral blindness rates per case vary from $2.5 \%$ to $8 \%$. Blindness registry data from Denmark suggest a glaucoma blindness rate of $5 \%$ per case. ${ }^{47}$ Glaucoma blindness rates in developing countries are probably higher than in Europe and the United States, assuming that in developed countries more of those affected are under therapy and that treatment is somewhat effective. Thus, the worldwide estimate for blindness/case is likely to be higher than the $8 \%$ rate among African Americans. If $10 \%$ of those with glaucoma in the world are blind and if the prevalence estimates here are accurate, the resultant estimate is 6.7 million blind by the year 2000. Thus, while some of our assumptions differ, the other recent report and this one
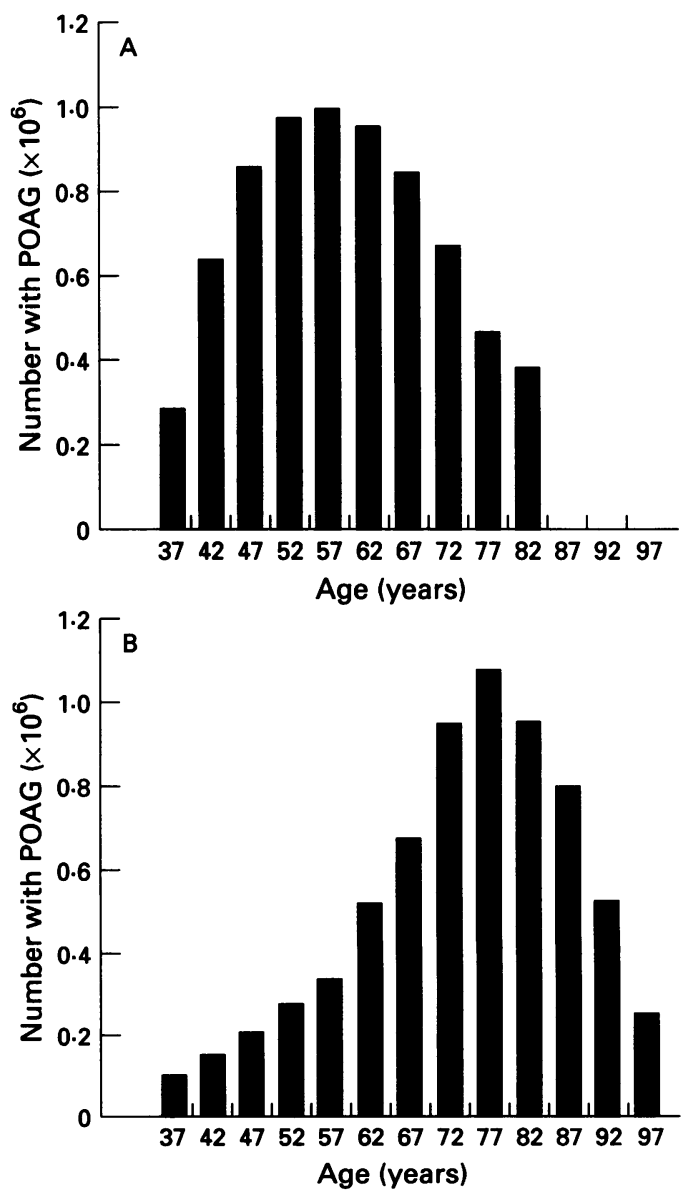

Figure 2 Comparison of primary open angle glaucoma (POAG) distribution among African $(A)$ and European derived $(B)$ groups of people. All those over age 80 in the African data are grouped in one age stratum, while in the European data, the proportion of those over 80 years of age justified four additional 5 year groupings. 
come to similar conclusions about the magnitude of the glaucoma blindness problem. By these estimates, glaucoma is, or soon will be, the second largest cause of bilateral blindness in the world after cataract. ${ }^{48}$ In addition, typical blindness statistics do not include the significant functional loss in glaucoma before bilateral blindness, often including monocular blindness and loss of mid peripheral visual field function and stereopsis.

Among people with glaucoma in developed countries only half are likely to be known to the health care system. In developing countries, the number is surely less. Because OAG is asymptomatic before blindness, patients are often unaware of their disease. Acute attacks of ACG are more likely to lead to presentation for care; hence, statistics based on clinic based data tend to overestimate the proportion of ACG compared with OAG. This bias was avoided here for much of the world by using survey based data. Lay people may assume that it is satisfactory to wait until blindness occurs, believing that it can be reversed as is true of cataract blindness. Since glaucoma blindness is irreversible, educational efforts in blindness prevention must target high risk populations with this information. In part, the low rate of glaucoma detection also results from the frustration of health care providers with impractical screening methods and the perceived inability to offer effective therapy for glaucoma.

Screening for glaucoma requires either the informed assessment of optic disc appearance or a functional test of peripheral visual function. It is inherently more difficult ${ }^{49}$ than the identification of cataract or trachoma, two other important causes of visual loss. Furthermore, there is no general agreement on criteria for glaucoma diagnosis. Despite a diversity of definitions, prevalence studies among European derived people come to relatively similar conclusions regarding its importance as a cause of vision loss. The recognition that glaucoma is the second most important cause of blindness worldwide should stimulate interest in better case detection. It is not necessary (and perhaps not even desirable) in many regions of the world to identify the earliest cases of glaucoma in order to have an impact. Given the relatively low disability/case ratio, the recognition of those at greatest risk of blindness would be a prudent approach. Initially at least, methods should be used that are sensitive enough to find those with moderate to severe glaucoma damage. This approach will have better specificity, decreasing the burden of examination of those improperly identified at screening. Furthermore, those already damaged may be more likely to agree to undergo therapy.

The therapy for glaucoma is less attractive to patients than cataract surgery, since vision can be retained, but not restored. Eyedrop treatment to lower IOP has been the initial therapy in developed countries, but its effectiveness and efficacy are being questioned. Daily medical treatment is expensive and subject to poor patient compliance. Initial surgery may be more effective at IOP lowering ${ }^{50}$ and is being compared with initial eyedrops in a US clinical trial. Antifibrotic agents as adjuncts to surgery ${ }^{5152}$ may produce acceptable rates of trabeculectomy success, especially if complications such as transient low IOP can be managed by releasable suture techniques. ${ }^{5354}$ Coordination of glaucoma surgery with cataract surgery programmes would take advantage of economies of scale.

These prevalence estimates are based on a relatively small number of people detected in surveys, and are subject to the assumptions presented. Hopefully, others will generate additional data and improve the intuitive approach. Further studies of glaucoma prevalence are urgently needed in the groups of countries included here - China, India, South Asia, Latin America, and the Near East. Screening for ACG, which may represent half of worldwide glaucoma, is hampered by inadequate methods and lack of standardised diagnostic criteria.

Among the regions of the world, there are striking differences in the number of people affected by glaucoma owing to variation in age distributions. The appropriate age at which screening begins to be most effective in African people is 30 years, because of the earlier onset of disease and the high proportion of young people in this population. For the European derived, it seems most efficient to screen those over 50 years of age. Expected changes in world population will continue to increase the number and proportion of older people. The concomitant increases in those with cataract and glaucoma will expand the need for diagnostic and therapeutic services.

Supported in part by EY 01765 (core facility grant) and RR 04060 (shared instrumentation (core facility grant) and RR Wilmer Institute by the National Eye Institute, National Wilmer Institute by the National Eye
Institutes of Health, Bethesda, MD, USA.

Institutes of Health, Bethesda, MD, USA.
Alfred Sommer, MD, Joanne Katz, DSc, and Yulan Ding, MS, provided helpful criticism and biostatistical consultation.

1 Quigley HA. Open-angle glaucoma. N Engl f Med 1993 328: $1097-106$.

2 Sommer A, Tielsch JM, Quigley HA, Gottsch JD, Javitt J Singh K. Relationship between intraocular pressure and primary open angle glaucoma among white and black Americans: the Baltimore eye survey. Arch Ophthalmol 1991; 109: 1090-5.

3 Congdon N, Wang F, Tielsch JM. Issues in the epidemiology and population-based screening of primary angle-
closure glaucoma. Surv Ophthalmol 1992; 36: 411-23.

4 Quigley HA. A model of glaucoma prevalence and incidence in the United States. (Submitted for publication.)

Bankes JLK, Perkins ES, Tsolakis S, Wright JE. Bedford Glaucoma survey. BMF 1968; 1: 791-6.

6 Bengtsson B. The prevalence of glaucoma. $\mathrm{Br} \mathcal{F}$ Ophthalmo 1981; 65: 46-9.

7 Coffey M, Reidy A, Wormald R, Xian WX, Wright L Courtney $P$. Prevalence of glaucoma in the west of Ireland. Br f Ophthalmol 1993; 77: 17-21.

8 Gibson JM, Rosenthal AR, Lavery J. A study of the prevalence of eye disease in the elderly in an English community. Trans Ophthalmol Soc UK 1985; 104: 196-203.

9 WHO. Glaucoma in Malta. Report of a workshop. Malta: WHO/PBL/90.21, 19-21 Oct 1989.

10 Hollows FC, Graham PA. Intra-ocular pressure, glaucoma, and glaucoma suspects in a defined population. $B r f$ aphthalmol 1966; 50: 570-86.

11 Hyams SW, Keroub C, Pokotilo E. The computer in clinical research. Prevalence of glaucoma. Doc Ophthalmol 1977; 43: 17-21.

12 Klein BEK, Klein R, Sponsel WE, Franke T, Cantor LB, Martone J, et al. Prevalence of glaucoma. The Beaver Dam eye study. Ophthalmology 1992; 99: 1499-504.

$13 \mathrm{Kahn} \mathrm{HA,} \mathrm{Milton} \mathrm{RC.} \mathrm{Alternative} \mathrm{definitions} \mathrm{of} \mathrm{open-angle}$ glaucoma. Effect on prevalence and associations in the Framingham Eye Study. Arch Ophthalmol 1980; 98 2172-7. 
14 Leibowitz HM, Kreuger DE, Maunder LR. The Framingham Eye Study Monograph. Surv Ophthalmol 1980; 24 (suppl): 335-610.

15 Lindblom B, Thorburn W. Prevalence of visual field defects due to capsular and simple glaucoma in Halsingland, Sweden. Acta Ophthalmol 1982; 60: 353-61.

16 Martinez GS, Campbell AJ, Reinken J, Allan BC. Prevalence of ocular disease in a population study of subjects 65 years old and older. Am F Ophthalmol 1982; 94: jects 65 181-9.

17 Ringvold A, Blika S, Elsas T, Guldahl J, Brevik T, Hesstvedt $\mathrm{P}$, et al. The Middle-Norway eye-screening study. II. Prevalence of simple and capsular glaucoma. Acta Ophthalmol 1991; 69: 273-80.

18 Rouhiainen H, Terasvirta M. Kuopio Eye Survey (KEYS). Acta Ophthalmol 1990; 68: 554-8.

19 Segal P, Skwierczynska J. Mass screening of adults for glaucoma. Ophthalmologica 1967; 153: 336-48.

20 Sommer A, Tielsch JM, Katz J, Quigley HA, Gottsch JD, Javitt JC, et al. Racial differences in the cause-specific prevalence of blindness in East Baltimore. $N$ Engl $\Im$ Med prevalence of blind

21 Tielsch JM, Sommer A, Katz J, Royall RM, Quigley HA, Javitt J. Racial variations in the prevalence of primary open angle glaucoma: the Baltimore eye survey. $f A M A$ 1991; 266: 369-74.

22 Stromberg U. Ocular hypertension. Frequency, course and relation to other disorders occurring in glaucoma, as seen from mass survey of all inhabitants over forty years of age in a Swedish town. Acta Ophthalmol (Kbh) 1962; 69 (suppl): $1-73$.

23 Dielemans I, Vingerling JR, Wolfs RCW, Hofman A Grobbee DE, deJong PTVM. The prevalence of primary open-angle glaucoma in a population-based study in The Netherlands. Ophthalmology 1994; 11: 1851-5.

24 Leske MC, Connell AMS, Schachat AP, Hyman L, the Barbados Eye Study Group. The Barbados eye study. Prevalence of open angle glaucoma. Arch Ophthalmol 1994; 112: 921-9.

25 Mason RP, Kosoko O, Wilson MR, Martone JP, Cowan $\mathrm{CL}, \mathrm{Gear} \mathrm{JC}$, et al. National survey of the prevalence and risk factors of glaucoma in St Lucia, West Indies. risk factors of glaucoma in St

26 David R, Duval DON, Luntz MH. The prevalence and management of glaucoma in an African populations. $S A f r$ Arch Ophthalmol 1984; 10: 55-62.

27 Neumann E, Zauberman H. Glaucoma survey in Liberia. Am f Ophthalmol 1965; 59: 8-12.

28 Quigley HA, West SK, Munoz B, Mmbaga BBO, Glovinsky Y. Examination methods for glaucoma prevalence surveys. Arch Ophthalmol 1993; 111: 1409-15.

29 Wallace J, Lovell HG. Glaucoma and intraocular pressure in Jamaica. Am $\mathcal{f}$ Ophthalmol 1969; 67: 93-100.

30 Kosoko O, Quigley HA, Vitale S, Enger C, Tielsch JM, Kerrigan LA. Risk factors for non-compliance with glaucoma follow-up visits. Invest Ophthalmol Visual Sci (ARVO Abstracts) 1995; 36: S80.

31 Shiose Y, Kitazawa Y, Tsukahara S, Akamatsu T, Mizokami K, Futa R, et al. Epidemiology of glaucoma in Japan - a nationwide glaucoma survey. Fpn $\mathcal{f}$ Ophthalmol 1991; 35: 133-55.

$32 \mathrm{Hu} \mathrm{Z}$, Zhao ZL, Dong FT. An epidemiologic investigation of glaucoma in Beijing and Shun-yi County. Chin 7 of glaucoma in Beijing and

33 Congdon NG, Quigley HA, Hung PT, Wang TH, Ho TC.
The impact of age, cataract and visual acuity on wholefield scotopic sensitivity screening for glaucoma in rura Taiwan. Arch Ophthalmol 1995; 113: 1138-43.

34 Congdon NG, Quigley HA, Hung PT, Wang TH, Ho TC Screening techniques for angle closure glaucoma in rural Taiwan. Acta Ophthalmol 1996 (in press).

35 Salmon JF, Mermoud A, Ivey A, Swanevelder SA, Hoffman $M$. The prevalence of primary angle closure glaucoma and M. The prevalence of primary angle closure glaucoma and open angle glaucoma in Mamre, Western

36 Das BN, Thompson JR, Patel R, Rosenthal AR. The prevalence of eye disease in Leicester: a comparison of adults of Asian and European descent. $\mathcal{f}$ Roy Soc Med 1994; 87: 219-22.

37 Leydhecker W. A glaucoma survey in South India. Doc Ophthalmol 1984; 57: 357-9.

38 Rauf A, Ong PS, Pearson RV, Wormald RPL. A pilot study into the prevalence of ophthalmic disease in the Indian population of Southall. $\mathcal{f}$ Roy Soc Med (UK) 1994; 87: 78-9.

39 Sarda RP, Charan H, Khetarpal RC. Screening of 1000 cases for the incidence of simple glaucoma over the age of 35 years. $\mathcal{F}$ All-India Ophthalmol Soc 1967; 15: 222-9.

$40 \mathrm{Lim}$ ASM. The pattern of ocular diseases in Singapore. Trans Australian Coll Ophthalmol 1971; 3: 122-5.

41 Bechetoille A, Aouchiche M, Hartani D. L'etude de Touggourt, une proposition pour le depistage de masse des glaucomes chroniques par l'examen du disque optique. F Fr Ophtalmol 1980; 3: 495-500.

42 Thomson IM, Chumbley LC. Eye disease in the West Bank and Gaza Strip. Br f Ophthalmol 1984; 68: 598.

43 Tabbara KF, Ross-Degnan D. Blindness in Saudi Arabia. FAMA 1986; 255: 3378-84.

44 Al Faran MF, Al-Rajhi AA, Al-Omar OM, Al-Ghamdi SA Jabak $M$. Prevalence and causes of visual impairment and blindness in the Southern Western region of Saudi Arabia. Int Ophthalmol 1993; 17: 161-5.

45 Foster A, Johnson G. Magnitude and causes of blindness in the developing world. Int Ophthalmol 1990; 14: 135-40.

46 Thylefors B, Negrel A-D. The global impact of glaucoma. Bull World Health Org 1994; 72: 323-6.

47 Fuchs HJ, Nissen KR, Goldschmidt E. Glaucoma blindness in Denmark. Acta Ophthalmol 1992; 70: 73-8.

48 Thylefors B, Negrel A-D, Pararajasegaram R. Epidemiologic aspects of global blindness prevention. Curr Opin Ophthalmol 1992; 3: 824-34.

49 Tielsch JM, Katz J, Singh K, Quigley HA, Gottsch JD, Javitt $\mathrm{J}$, et al. A population-based evaluation of glaucoma screening: the Baltimore eye survey. Am F Epidemiol 1991; 134: $1102-10$.

50 Jay JL, Murray SB. Early trabeculectomy versus conventional management in primary open angle glaucoma. $\mathrm{Br}$ tional management in primary

51 Heuer DK, Parrish RK, Gressel MG. 5-Fluorouracil and glaucoma filtering surgery. Ophthalmology 1986;93 $1537-46$.

52 Chen CW, Huang HT, Bair JS, Lee CC. Trabeculectomy with simultaneous topical application of mitomycin $\mathrm{C}$ in refractory glaucoma. ₹ Ocul Pharmacol 1990; 6: 175-82.

53 Hoskins HD, Migliazzo C. Management of failing filtering blebs with the argon laser. Ophthalmol Surg 1984; 15: 731-3.

54 Wilson RP. Technical advances in filtration surgery. In: McAllister JA, Wilson RP, eds. Glaucoma. Stoneham, MA: Butterworths, 1986: 243-50. 